\title{
THE EFFECT OF NOR-EPINEPHRINE UPON PULMONARY ARTERIOLAR RESISTANCE IN MAN ${ }^{1}$
}

\author{
BY NOBLE O. FOWLER, RICHARD N. WESTCOTT, ${ }^{2}$ RALPH C. SCOTT, AND \\ JOHNSON MCGUIRE \\ (From the Cardiac Laboratory, Cincinnati General Hospital, Department of Internal Medicine, \\ University of Cincinnati, Cincinnati, O.)
}

(Submitted for publication January 6, 1951; accepted, March 12, 1951)

Nor-epinephrine is a sympathomimetic drug similar in structure to epinephrine, but lacking a methyl group on the nitrogen atom contained in the latter compound (1). Its levo-isomer is twice as active as the optically inactive preparation. Some investigators believe that 1-nor-epinephrine is identical with sympathin $\mathrm{E}(1)$; others feel that it is more likely that nor-epinephrine is the precursor of epinephrine at adrenergic nerve endings $(2,3)$. Goldenberg and associates (1) found that in man 1-nor-epinephrine increases total peripheral resistance, and in further contrast to epinephrine, does not increase the cardiac output. Goldenberg also (1) found a consistent elevation in pulmonary artery pressure during the infusion of 1-nor-epinephrine in man. However, since he did not measure pulmonary venous pressure, one cannot determine from his study the primary site of action of 1-nor-epinephrine in producing transient pulmonary hypertension. For these reasons it seemed desirable to investigate further the action of 1-nor-epinephrine upon the pulmonary circulation.

The purpose of the study reported here is to determine how 1-nor-epinephrine produces pulmonary arterial hypertension in man. In man the pulmonary venous pressure may not ordinarily be measured directly. However, Hellems and coworkers (4) have described a method of obtaining pulmonary "capillary" pressure, and have shown that in animals the pulmonary "capillary" pressure varies with the pulmonary venous pressure. If pulmonary artery pressure, pulmonary "capillary" pressure and cardiac output are determined simultaneously, the pulmonary arteriolar resistance may be calculated (5). If nor-epinephrine produces pulmonary hypertension by pulmonary ar-

\footnotetext{
1 This study was supported by Research Contract V1001 M-432 Veterans Administration.

2 Public Health Service Postdoctorate Research Fellow of the National Heart Institute.
}

terial constriction, then a rise in pulmonary arteriolar resistance is to be expected during the pulmonary hypertension resulting from its exhibition.

\section{MATERIAL}

Thirteen subjects were studied. Eleven had normal hearts as shown by physical examination, $\mathrm{X}$-ray, and the electrocardiogram. One (E. B.) was convalescing from beriberi heart disease, with only residual tachycardia. One (C. F.) had a systolic murmur at the cardiac apex and a pulmonary "capillary" pressure tracing suggestive of incompetency of the mitral valve (6). C. F. had also moderate elevation of the mean pulmonary arterial pressure while in the resting state. As controls, six subjects with various types of cardio-pulmonary disease were studied.

\section{METHOD}

All subjects except E. B. were studied in the fasting condition, sedated by 0.1 or $0.2 \mathrm{gm}$. of seconal given two to two and a half hours prior to study. Cardiac catheterization was performed as described previously (7). A double lumen catheter was used, so that pulmonary "capillary" pressure and pulmonary arterial pressure could be measured simultaneously. Pulmonary "capillary" pressure was obtained by the method of Hellems and co-workers (4). The criteria of satisfactory pulmonary "capillary" pressures were (1) the nature of the pressure curve, showing " $a$ " and " $c$ " waves; (2) the peripheral location of the catheter tip in the lung; and (3) the securing of a specimen of blood saturated with oxygen from the wedged catheter tip. This last was not always possible, since in some instances, no blood could be obtained from the wedged catheter tip. Brachial artery pressure was obtained through an 18 gauge indwelling Cournand needle. Simultaneous electrocardiograms, ballistocardiograms, brachial arterial, pulmonary arterial, and pulmonary "capillary" pressures were recorded by means of a five channel optical oscillograph.

Cardiac outputs were determined by the direct Fick method as described previously (8). Duplicate samples of expired air were analyzed for $\mathrm{CO}_{2}$ and $\mathrm{O}_{2}$ and required to check within $0.03 \%$. Duplicate blood samples, collected during the collection of expired air, were required to check within 0.2 vol.\%.

Resting cardiac outputs were obtained after the catheter had been in place 15 to 30 minutes or more. After the 
TABLE I

The effect of l-nor-epinephrine upon pulmonary artery and brachial artery pressure

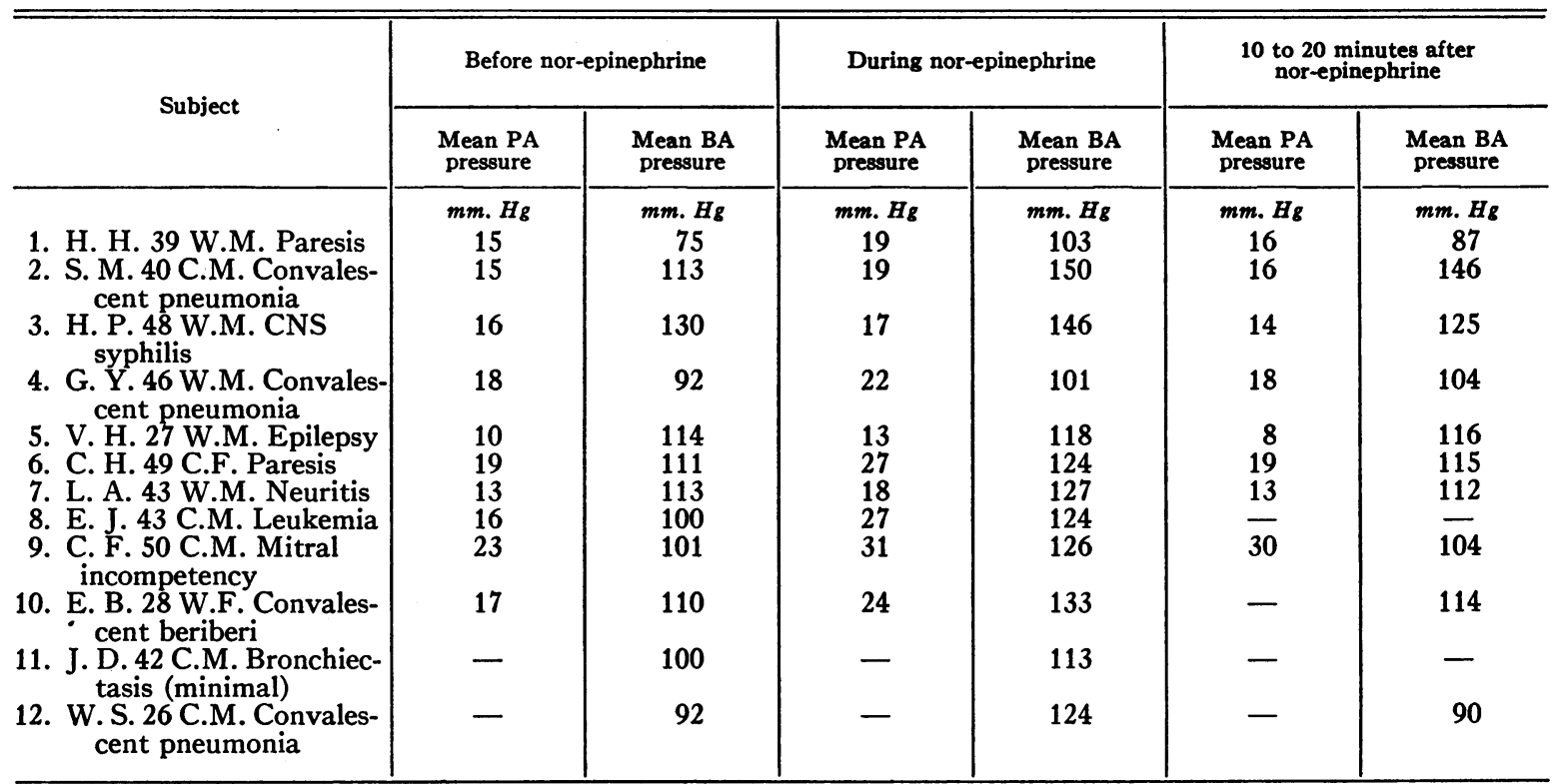

blood and gas samples for the resting cardiac output had been collected, the subjects were given 0.2 to 0.4 microgram of 1-nor-epinephrine ${ }^{3}$ per kilogram body weight per minute into the distal aperture of the catheter lying within the pulmonary artery. When a maximum effect upon the blood pressures had been obtained, usually within three to five minutes, blood and gas samples for a second cardiac output were collected. The infusion of 1-nor-epinephrine was continued during the collection of samples. Pressure recordings were obtained immediately before and immediately after the collection of blood samples. In six cases a third cardiac output and set of pressure recordings were obtained 10 to 20 minutes after discontinuing the 1-nor-epinephrine infusion. More than one resting cardiac output would have been desirable but was not obtained because of the danger of fatiguing the subject.

Six control subjects were studied by the above method. They received fluids comparable in volume and rate of infusion to those received by the subjects to whom norepinephrine was administered. Following resting measurements of cardiac output and pressures, $5 \%$ dextrose solution was infused into the pulmonary artery for a period of time roughly equivalent to that required for the infusion of 1-nor-epinephrine. Then resting measurements of cardiac output and pressures were repeated.

Mean pulmonary arterial, brachial arterial and pulmonary "capillary" pressures were determined by planimetry. Measurements were made over two or more respiratory cycles. Pressures taken just before and just after each cardiac output were averaged in obtaining the final result. A point $10 \mathrm{~cm}$. anterior from the back of

3 Supplied through the courtesy of Winthrop-Stearns Company, Buffalo, New York. the horizontal subject was taken as the zero point in pressure measurements.

Pulmonary arteriolar resistance was calculated by the formula :

$$
\mathrm{R}=\frac{\mathrm{PA}-\mathrm{PC}}{\mathrm{CO}} \times 1,332 .
$$

Where $\quad \mathrm{R}=$ arteriolar resistance in dynes $/ \mathrm{sec} . / \mathrm{cm} .^{-6}$

$\mathrm{PA}=$ mean pulmonary artery pressure

$\mathrm{PC}=$ mean pulmonary "capillary" pressure

$\mathrm{CO}=$ cardiac output in cc. $/ \mathrm{sec}$.

Total peripheral resistance (TPR) was determined by the formula

$$
T P R=\frac{B A}{C O} \times 1,332 .
$$

Where $T P R=$ total peripheral resistance in dynes $/ \mathrm{sec} . /$

$\mathrm{BA}=$ mean brachial artery pressure

$\mathrm{CO}=$ cardiac output in cc./sec.

Systemic peripheral resistance was determined according to the formula:

$$
\mathrm{SPR}=\frac{\mathrm{BA}-\mathrm{RA}}{\mathrm{CO}} \times 1,332 .
$$
Where SPR = systemic peripheral resistance in dynes/

BA $=$ mean brachial arterial pressure

$\mathrm{CO}=$ cardiac output in cc./sec.

$\mathrm{RA}=$ mean right auricular pressure

\section{RESULTS}

Pulmonary arterial and brachial arterial pressure (Table I). In each of 10 subjects a definite rise in pulmonary artery pressure occurred. The mean rise in pulmonary artery pressure was $5 \mathrm{~mm}$. $\mathrm{Hg}$ 
TABLE II

Statistical table of changes induced by l-nor-epinephrine

\begin{tabular}{|c|c|c|c|c|c|}
\hline & $\begin{array}{l}\text { No. } \\
\text { cases }\end{array}$ & $t-1 \%$ & $\underset{\text { level }}{-5 \%}$ & Ob- & $\stackrel{p}{p}$ \\
\hline 1. Pulmonary artery & 10 & 3.250 & - & 5.7 & $<0.001$ \\
\hline $\begin{array}{l}\text { 2. Brachial artery mean } \\
\text { pressure }\end{array}$ & 12 & 3.106 & - & 6.99 & $<0.001$ \\
\hline 3. Pulmonary "capillary" & 9 & 3.355 & & 6.33 & $<0.001$ \\
\hline $\begin{array}{l}\text { 4. Cardiac output } \\
\text { 5. Heart rate } \\
\text { 6. Total peripheral resist- } \\
\text { ance }\end{array}$ & $\begin{array}{l}10 \\
12 \\
11\end{array}$ & $3 . \overline{106}$ & $\frac{2.262}{2.228}$ & $\begin{array}{l}2.270 \\
4.3 \\
2.6\end{array}$ & $\begin{array}{l}<0.05 \\
<0.01 \\
<0.05\end{array}$ \\
\hline $\begin{array}{l}\text { 7. Arteriovenous oxygen } \\
\text { difference }\end{array}$ & 11 & - & 2.228 & 1.85 & $<0.1$ \\
\hline $\begin{array}{l}\text { 8. Stroke volume } \\
\text { 9. Correlation of rise in } \\
\text { P. A. and P. C. mean } \\
\text { pressure }\end{array}$ & 11 & $r=\overline{0.76 t}$ & 2.228 & $r=0.85 t$ & $\begin{array}{l}<0.1 \\
<0.01\end{array}$ \\
\hline
\end{tabular}

* From Fisher and Yates (10).

$\dagger$ Correlation coefficient (11).

or $33 \%$ over the resting value. Each of 12 subjects had a definite rise in brachial arterial pressure. The mean rise in brachial artery pressure was $20 \mathrm{~mm}$. $\mathrm{Hg}$ or $19 \%$. Ten to 20 minutes after cessation of nor-epinephrine administration, the pressure had fallen in all cases in the pulmonary artery, and in all cases save one in the brachial artery. However, 10 to 20 minutes was insufficient time for complete subsidence of nor-epinephrine effect in every case. The changes in both pulmonary artery and brachial artery pressures were statistically significant (9) at the $p<0.001$ level (Table II).

Cardiac output (Table III). A significant rise (i.e., $10 \%$ above the resting level [8]) in cardiac output was found in only one of the 11 cases. In this case the cardiac output rose still further after withdrawal of the nor-epinephrine; therefore the observed elevation was attributed to anxiety rather than the effect of the drug. A significant fall in output was observed in five subjects. In the five remaining subjects there was no significant change in cardiac output. Statistical analysis (Table II) revealed a significant decline in cardiac output when the group was considered as a whole ( $p=$ $.05)$. The low cardiac index of subject C. F. is attributed to heavy sedation rather than to cardiac failure, since the subject had a normal arteriovenous oxygen difference of 3.9 vol. $\%$. This subject was apparently unduly sensitive to barbiturates, and was roused with difficulty during the study, although he had received only $0.2 \mathrm{gm}$. of seconal. His oxygen consumption was quite low, being only $74.6 \mathrm{cc}$./sq. m./min.

Pulmonary "capillary" pressure and pulmonary arteriolar resistance (Table IV). There was a definite rise in pulmonary "capillary" pressure during the administration of nor-epinephrine in each instance. The mean rise was $6 \mathrm{~mm}$. $\mathrm{Hg}$ or $64 \%$, close to the mean rise in pulmonary artery pressure of $5 \mathrm{~mm} . \mathrm{Hg}$. Ten to 20 minutes after cessation of the nor-epinephrine infusion the pulmonary "capillary" pressures had fallen toward the original levels in all cases. The pulmonary arteriolar resistance showed no significant change in four subjects, a definite fall in three, and a definite rise in two subjects. The pulmonary arteriolar resistances showed much less tendency then pulmonary artery

TABLE III

The effect of l-nor-epinephrine upon cardiac output and heart rate

\begin{tabular}{|c|c|c|c|c|c|c|}
\hline \multirow{2}{*}{ Subject } & \multicolumn{2}{|c|}{ Before nor-epinephrine } & \multicolumn{2}{|c|}{ During nor-epinephrine } & \multicolumn{2}{|c|}{ After nor-epinephrine } \\
\hline & $\begin{array}{c}\text { Cardiac } \\
\text { Index }\end{array}$ & Heart rate & $\begin{array}{c}\text { Cardiac } \\
\text { Index }\end{array}$ & Heart rate & $\begin{array}{c}\text { Cardiac } \\
\text { Index }\end{array}$ & Heart rate \\
\hline $\begin{array}{l}\text { 1. H. H. } 39 \text { W.M. } \\
\text { 2. S. M. } 40 \text { C.M. } \\
\text { 3. H. P. } 48 \text { W.M. } \\
\text { 4. G. Y. } 46 \text { W.M. } \\
\text { 5. V. H. } 27 \text { W.M. } \\
\text { 6. C. H. } 49 \text { C.F. } \\
\text { 7. L. A. } 43 \text { W.M. } \\
\text { 8. E. J. } 43 \text { C.M. } \\
\text { 9. C. F. } 50 \text { C.M.* } \\
\text { 10. J. D. } 42 \text { C.M. } \\
\text { 11. W. S. } 26 \text { C.M. } \\
\text { 12. E. B. } 28 \text { W.F. }\end{array}$ & $\begin{array}{c}\text { L/sq. m./min. } \\
3.0 \\
3.1 \\
3.0 \\
2.3 \\
3.2 \\
3.4 \\
4.3 \\
3.3 \\
1.9 \\
2.7 \\
3.6 \\
\end{array}$ & $\begin{array}{c}\text { per min. } \\
72 \\
66 \\
64 \\
82 \\
65 \\
82 \\
92 \\
65 \\
45 \\
72 \\
70 \\
98\end{array}$ & $\begin{array}{c}\text { L/sq. m./min. } \\
2.9 \\
3.2 \\
2.6 \\
3.3 \\
3.3 \\
3.4 \\
3.5 \\
3.4 \\
1.3 \\
2.5 \\
2.6 \\
\end{array}$ & $\begin{array}{c}\text { per min. } \\
60 \\
50 \\
50 \\
65 \\
55 \\
78 \\
60 \\
70 \\
38 \\
68 \\
55 \\
68\end{array}$ & $\begin{array}{c}\text { L/sq. m./mix. } \\
3.8 \\
3.3 \\
\overline{3.8} \\
3.9 \\
\overline{4.7} \\
\overline{1.9} \\
3.0 \dagger \\
-\end{array}$ & $\begin{array}{c}\text { per min. } \\
76 \\
63 \\
68 \\
88 \\
64 \\
86 \\
88 \\
80 \\
50 \\
68 \dagger \\
74 \\
\end{array}$ \\
\hline
\end{tabular}

* Heavily sedated.

† Second control before drug administration. 
TABLE IV

The effect of l-nor-epinephrine upon pulmonary "capillary" pressure and pulmonary arteriolar resistance

\begin{tabular}{|c|c|c|c|c|c|c|}
\hline \multirow{2}{*}{ Subject } & \multicolumn{2}{|c|}{ Before nor-epinephrine } & \multicolumn{2}{|c|}{ During nor-epinephrine } & \multicolumn{2}{|c|}{ After nor-epinephrine } \\
\hline & P. C. & Pulm. res. & P. C. & Pulm. res. & P. C. & Pulm. res. \\
\hline $\begin{array}{l}\text { 1. H. H. } 39 \text { W.M. } \\
\text { 2. S. M. } 40 \text { C.M. } \\
\text { 3. H. P. } 48 \text { W.M. } \\
\text { 4. G. Y. } 46 \text { W.M. } \\
\text { 5. V. H. } 27 \text { W.M. } \\
\text { 6. C. H. } 49 \text { G.F. } \\
\text { 7. L. A. } 43 \text { W.M. } \\
\text { 8. E. J. } 43 \text { C.M. } \\
\text { 9. C. F. } 50 \text { C.M. }\end{array}$ & $\begin{array}{c}m m . H g \\
10 \\
9 \\
7 \\
11 \\
6 \\
9 \\
9 \\
7 \\
14\end{array}$ & \begin{tabular}{|c|} 
dynes $/$ sec. $/ \mathrm{cm}^{-\gamma}$ \\
89 \\
95 \\
133 \\
131 \\
66 \\
151 \\
41 \\
114 \\
202
\end{tabular} & $\begin{array}{c}m m . H 8 \\
17 \\
13 \\
9 \\
17 \\
11 \\
15 \\
12 \\
17 \\
22\end{array}$ & $\begin{array}{c}\text { dymes } / \mathrm{sec} . / \mathrm{cm} .-8 \\
40 \\
95 \\
138 \\
65 \\
37 \\
163 \\
75 \\
122 \\
326\end{array}$ & $\begin{array}{c}m m . H g \\
12 \\
10 \\
5 \\
12 \\
7 \\
6 \\
6 \\
\frac{16}{16}\end{array}$ & $\begin{array}{c}\text { dynes } / \mathrm{sec} . / \mathrm{cm} .-5 \\
46 \\
\frac{90}{69} \\
\frac{27}{63} \\
\frac{-133}{333}\end{array}$ \\
\hline
\end{tabular}

mean pressures to return toward the original level in those cases where they were altered. The observed elevation in pulmonary "capillary" pressure was significant statistically $(\mathrm{p}<0.001)$ (Table II).

Total peripheral resistance and heart rate (Tables III and $V$ ). A significant increase in total peripheral resistance (TPR) was found in nine of 11 subjects during the infusion of nor-epinephrine. There was no significant change in one subject, and a decline in resistance in another. The mean rise was 497 dynes $/ \mathrm{sec} . / \mathrm{cm}^{-5}$ or $31 \%$. The heart rate slowed in 11 of the 12 subjects. The one subject who did not show slowing (E. J.) demonstrated a further rise in heart rate after the cessation of nor-epinephrine, suggesting a masking of the drug effect by some extraneous factor. Both

TABLE V

The effect of $l$-nor-epinephrine upon total peripheral resistance

\begin{tabular}{|c|c|c|c|}
\hline \multirow{2}{*}{ Subject } & $\begin{array}{c}\text { Before } \\
\text { nor-epi- } \\
\text { nephrine }\end{array}$ & $\begin{array}{c}\text { During } \\
\text { nor-epi- } \\
\text { nephrine }\end{array}$ & $\begin{array}{c}\text { After } \\
\text { nor-epi- } \\
\text { nephrine }\end{array}$ \\
\hline & TPR & TPR & TPR \\
\hline & $\begin{array}{c}\text { dymes/ } \\
\text { sec./cm. }->\end{array}$ & $\begin{array}{c}\text { dymes/ } \\
\text { sec./cm. } \rightarrow\end{array}$ & $\begin{array}{l}\text { dymes/ } \\
\text { sec./cm. }\end{array}$ \\
\hline $\begin{array}{l}\text { 1. H. H. } 39 \text { W.M. } \\
\text { 2. S. M. } 40 \text { C.M. } \\
\text { 3. H. P. } 48 \text { W.M. } \\
\text { 4. G. Y. } 46 \text { W.M. } \\
\text { 5. V. H. } 27 \text { W.M. } \\
\text { 6. C. H. } 49 \text { C.F. } \\
\text { 7. L. A. } 43 \text { W.M. } \\
\text { 8. E. J. } 43 \text { C.M. } \\
\text { 9. C. F. } 50 \text { C.M. } \\
\text { 10. J. D. } 42 \text { C.M. } \\
\text { 11. W. S. } 26 \text { C.M. }\end{array}$ & $\begin{array}{l}1,223 \\
1,727 \\
1,918 \\
1,704 \\
1,787 \\
1,539 \\
1,142 \\
1,227 \\
2,523 \\
1,615 \\
1,170\end{array}$ & $\begin{array}{l}1,698 \\
2,222 \\
2,474 \\
1,312 \\
1,802 \\
1,708 \\
1,609 \\
1,502 \\
4,557 \\
1,976 \\
2,187\end{array}$ & $\begin{array}{l}1,119 \\
2,160 \\
\overline{1,188} \\
1,478 \\
\overline{1,045} \\
\overline{2,637} \\
1,405^{*} \\
-\end{array}$ \\
\hline
\end{tabular}

* Duplicate observations before drug administration. heart rate and peripheral resistance returned toward resting values 10 to 20 minutes after withdrawal of the 1-nor-epinephrine. The observed bradycardia was statistically significant at the $p<0.001$ level and the observed increase in total peripheral resistance was significant statistically at the $\mathrm{p}<0.05$ level (Table II).

Right atrial pressure, right ventricular end diastolic pressure, and peripheral venous pressure. In each of three subjects in whom observations were made pressures within the right side of the heart rose during administration of the drug. In subject W. S. right atrial pressure was $29 \mathrm{~mm}$. water in the resting state. During 1-nor-epinephrine administration, the pressure rose to $82 \mathrm{~mm}$. water. After the drug was discontinued, right auricular pressure fell to $38 \mathrm{~mm}$. water. In subject E. B., right ventricular end diastolic pressure rose from $5 \mathrm{~mm}$. $\mathrm{Hg}$ to $14 \mathrm{~mm}$. $\mathrm{Hg}$ during l-nor-epinephrine infusion. Right atrial pressure also rose during the drug infusion but unfortunately the pressure was not measured at its peak and the rise was less striking than that in the right ventricular end diastolic pressure. In subject F. H. there was a striking rise in right atrial pressure during 1-nor-epinephrine infusion (Figures 1 and 2). A peripheral venous pressure curve was obtained simultaneously with the right atrial and peripheral artery pressure curve in this subject (Figure 2). There was an approximately equal rise in pressure in the peripheral vein and right atrium approximating $10 \mathrm{~mm} . \mathrm{Hg}$ in the right atrium and $11 \mathrm{~mm} . \mathrm{Hg}$ in the peripheral vein. However, the peak pressure rise occurred earlier in the peripheral vein than in the right atrium (Figure 1). 
MEAN PRESSURE CHANGES IN RIGHT ATRIUM, FEMORAL ARTERY AND PERIPHERAL VEIN IN PATIENT F.H. DURING L-NOR-EPINEPHRINE INFUSION

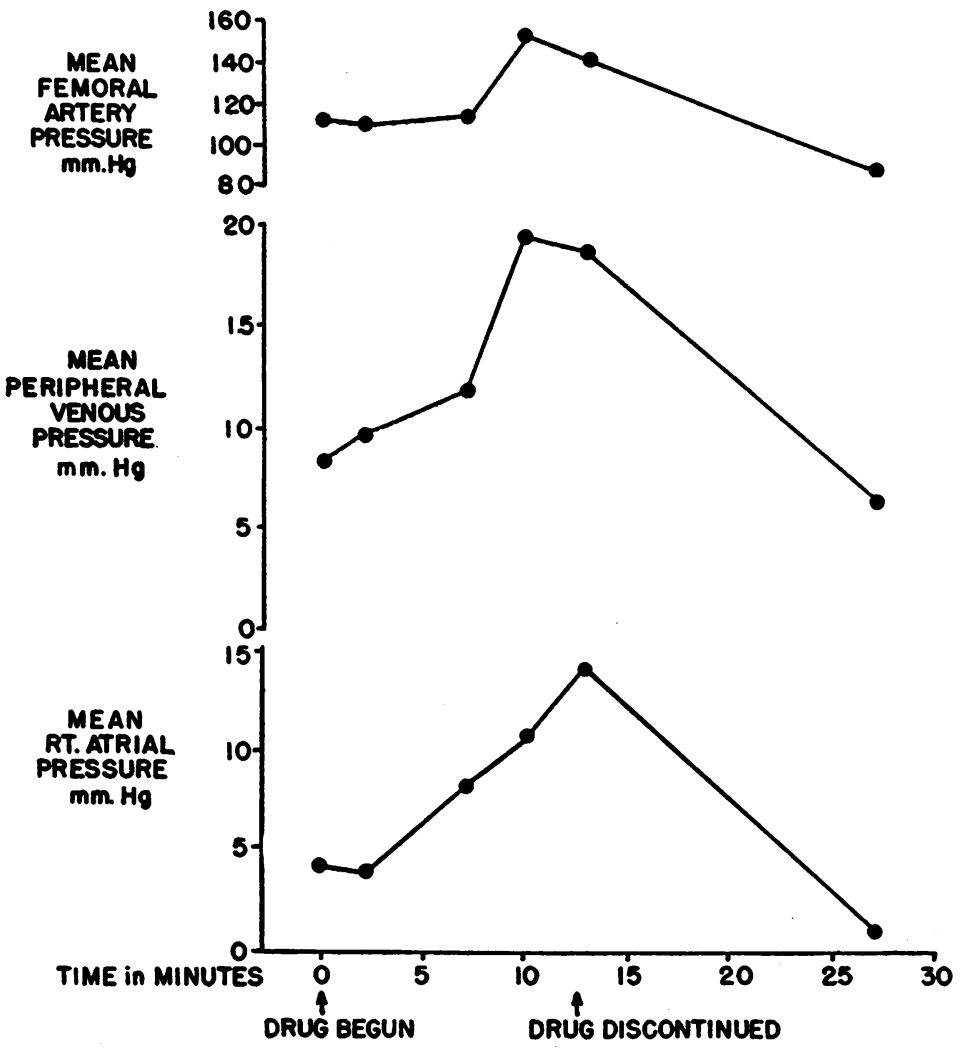

FIG. 1.

TABLE VI

Control subjects

\begin{tabular}{|c|c|c|c|c|c|c|c|c|c|c|c|c|}
\hline & \multicolumn{6}{|c|}{ First resting study } & \multicolumn{6}{|c|}{ Second resting study } \\
\hline & $\underset{\text { mean }}{\text { BA }}$ & $\underset{\text { mean }}{\text { PA }}$ & $\underset{\text { mean }}{P C}$ & $\mathrm{CO}$ & TPR & $\begin{array}{l}\text { Pulm. } \\
\text { res. }\end{array}$ & $\underset{\text { mean }}{\text { BA }}$ & $\underset{\text { mean }}{\mathbf{P A}}$ & $\underset{\text { mean }}{P C}$ & $\mathrm{CO}$ & TPR & $\begin{array}{l}\text { Pulm. } \\
\text { res. }\end{array}$ \\
\hline 1. R. J. 69 C.M. hyper- & 一 & 16.8 & 6.8 & $\begin{array}{c}L / \mathrm{min} . \\
3.6\end{array}$ & - & 223 & 一 & 16.4 & 8.8 & $\begin{array}{c}L / \min . \\
3.4\end{array}$ & 一 & 181 \\
\hline 2. M. L. 52 W.F. emphy- & 87.3 & 20.8 & 5.8 & 3.6 & 1,961 & 337 & 90.3 & 21.5 & 5.1 & 3.5 & 2,092 & 380 \\
\hline 3. M.S. 49 W.M. mitral & - & 53.8 & - & 3.7 & - & 一 & - & 49.5 & - & 3.9 & - & - \\
\hline 4. J. D. 48 C.M. bronchiec- & 99.6 & 一 & 12.8 & 4.9 & 1,615 & 一 & 93.4 & - & 11.8 & 5.3 & 1,405 & 一 \\
\hline 5. D. H. 61 W.M. cor & 65.3 & 38.4 & 一 & 4.4 & 1,963 & 一 & 65.7 & 36.3 & - & 4.2 & 2,050 & - \\
\hline $\begin{array}{l}\text { 6. F. B. } 18 \text { C.F. sickle cell } \\
\text { anemia }\end{array}$ & 一 & 18.6 & - & 8.6 & 一 & 一 & 一 & 16.8 & - & 7.9 & 一 & - \\
\hline
\end{tabular}

Mean pressures are expressed in $\mathrm{mm} . \mathrm{Hg}$.

Resistances are expressed in dynes $/ \mathrm{sec} . / \mathrm{cm}^{-6}$.

BA = brachial artery.

PA = pulmonary artery.

PC = pulmonary "capillary."

$\mathrm{CO}=$ cardiac output. 

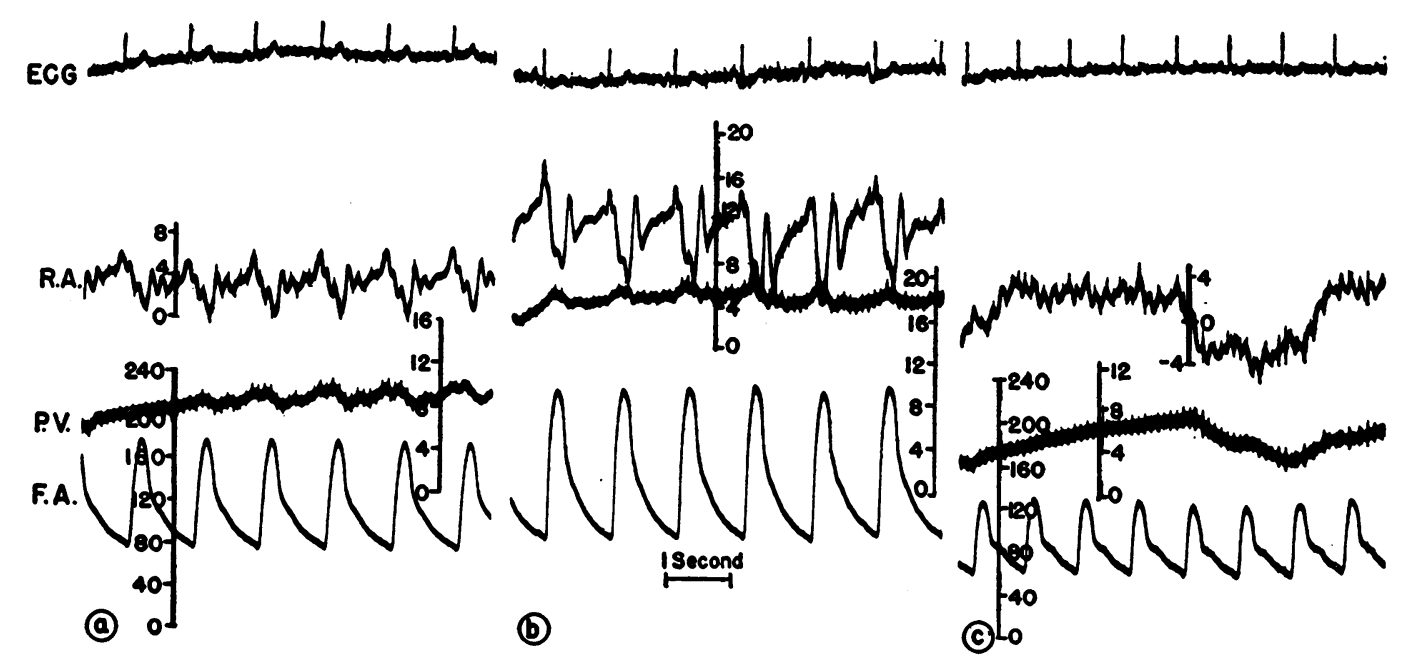

Fig. 2. Excerpted from Pressure Tracing of Patient F. H.

Section (a) is before 1-nor-epinephrine; (b) is at the peak response 13 minutes after beginning the infusion of 1-nor-epinephrine; (c) shows the return of pressure to resting levels 14 minutes after cessation of 1-nor-epinephrine infusion. In (a), mean femoral artery pressure is $111.6 \mathrm{~mm}$. $\mathrm{Hg}$; mean peripheral vein pressure is $8.4 \mathrm{~mm}$. $\mathrm{Hg}$; mean right atrial pressure is $4.2 \mathrm{~mm}$. $\mathrm{Hg}$. In (b), the mean femoral artery pressure has risen to $141.2 \mathrm{~mm}$. $\mathrm{Hg}$; mean peripheral vein pressure, to $18.7 \mathrm{~mm} . \mathrm{Hg}$; mean right atrial pressure, to $14.2 \mathrm{~mm}$. Hg. In (c) mean femoral artery pressure has fallen to $88.4 \mathrm{~mm}$. $\mathrm{Hg}$; mean peripheral vein pressure, to $6.3 \mathrm{~mm}$. $\mathrm{Hg}$; mean right atrial pressure, to $1.1 \mathrm{~mm}$. $\mathrm{Hg}$.

In order to exclude changes in right atrial pressure as a cause of increased total peripheral resistance, the observed values for right atrial pressure should be subtracted from the brachial pressure in the formula. This could not be done because right atrial pressures were not routinely measured. In one subject (W. S.) in whom this could be done, the systemic peripheral resistance was 1143 dynes/sec. $/ \mathrm{cm}^{-5}$ before and 2082 dynes/ sec. $/ \mathrm{cm}^{-5}$ during l-nor-epinephrine, showing an increase of $82 \%$.

In the six control subjects (Table VI), the second resting cardiac output varied less than $10 \%$ from the resting measurement. The mean variation in pulmonary artery pressure was $1.7 \mathrm{~mm}$. $\mathrm{Hg}$. The observed variations in brachial artery pressure, pulmonary "capillary" pressure, total peripheral resistance, and pulmonary arteriolar resistance are seen in Table VI.

\section{DISCUSSION}

The hemodynamic changes observed during an infusion of 1-nor-epinephrine consisted of increased pulmonary artery and brachial artery pressures, increased peripheral resistance, diminished cardiac output, and bradycardia, and confirm the observations of Goldenberg (1). The bradycardia was also observed by Judson and co-workers (12).

The mechanism of the increase in pressure in the pulmonary and peripheral arteries is not the same. There was a statistically significant elevation in total peripheral resistance during 1-norepinephrine administration; on the other hand, in only two of the nine cases studied was there an increase in pulmonary arteriolar resistance. In one of these (C. F.) the pulmonary "capillary" pressure rose within the critical range of 20-25 $\mathrm{mm} . \mathrm{Hg}$, at which level pulmonary resistance increases as a protective mechanism to prevent pulmonary edema (5). Thus it is quite probable that the rise in resistance in case $\mathrm{C}$. F. was not a direct effect of 1-nor-epinephrine, but an effect secondary to the increase in pulmonary venous pressure. An increase in pulmonary "capillary" pressure was observed in all cases following 1-nor-epinephrine, and the mean increase was nearly the same as the mean increase in pulmonary artery pressure. Therefore, the usual mechanism whereby 1-nor-epinephrine produces pulmonary hypertension in man is through an increase in pulmonary "capillary" or venous pressure. 
The rise in pulmonary artery pressure following 1-nor-epinephrine infusion is due to a rise in left atrial pressure for the following reasons. First, there is no consistent rise in pulmonary arteriolar resistance after the drug, thereby excluding constriction of the pulmonary arterioles as the mechanism of pressure elevation. Second, there is a significant correlation between the rise in the pulmonary artery and pulmonary "capillary" mean pressures during 1-nor-epinephrine infusion (Table II). Third, there is a definite rise in pulmonary "capillary" pressure following 1-nor-epinephrine which implies a rise in pulmonary venous pressure and thus a rise in left atrial pressure. Fourth, there is a rise in right atrial pressure after the drug, which also implies a concomitant rise in left atrial pressure (13).

One may speculate further as to the mechanism of elevation of right atrial pressure following 1-norepinephrine. Ranges and Bradley (14) and Bradley and Parker (15) in attempting to explain the rise in right atrial pressure after paredrinol and angiotonin, considered heart failure unlikely because there was no evidence of cardiac dilatation. They believed that an increase in venous tone, decreasing the total volume of the vascular system, might be responsible. Iglauer and Altschule (16) have shown that other sympathomimetic drugs-adrenaline and paredrine-increase the peripheral venous pressure. Ranges and Bradley also mentioned an increase in "cardiac tone" as the cause of the elevated right atrial pressure following angiotonin.

TABLE VII

Effect of l-nor-epinephrine upon A-V oxygen difference and upon stroke volume of the heart

\begin{tabular}{c|c|c|c|c}
\hline & \multicolumn{2}{|c|}{ Stroke volume (cc.) } & \multicolumn{2}{|c}{$\begin{array}{c}\text { A-V difference } \\
(c c . / 100 \text { cc. blood })\end{array}$} \\
\cline { 2 - 4 } Subject & $\begin{array}{c}\text { Before } \\
\text { 1-nor- } \\
\text { epinephrine }\end{array}$ & $\begin{array}{c}\text { During } \\
\text { 1-nor- } \\
\text { epinephrine }\end{array}$ & $\begin{array}{c}\text { Before } \\
\text { epor- } \\
\text { epinephrine }\end{array}$ & $\begin{array}{c}\text { During } \\
\text { l-nor- } \\
\text { epinephrine }\end{array}$ \\
\cline { 2 - 4 } 1. H. H. & 68 & 81 & 3.7 & 4.5 \\
2. C. F. & 71 & 58 & 3.9 & 5.5 \\
3. S. M. & 79 & 108 & 4.7 & 5.7 \\
4. H. P. & 85 & 94 & 4.5 & 5.2 \\
5. G. Y. & 53 & 95 & 4.7 & 4.7 \\
6. V. H. & 78 & 96 & 3.2 & 3.6 \\
7. C. H. & 70 & 74 & 4.0 & 3.2 \\
8. L. A. & 86 & 105 & 2.7 & 3.5 \\
9. E. J. & 100 & 94 & 5.3 & 4.4 \\
10. J. D. & 69 & 67 & 4.0 & 4.1 \\
11. W. S. & 89 & 82 & 3.0 & 4.6 \\
\hline
\end{tabular}

Although there was an increase in the mean A-V oxygen difference of $12 \%$ in the subjects studied, there was also an increase in the mean stroke volume of $13 \%$ (Table VII). The changes in stroke volume and $\mathrm{A}-\mathrm{V}$ oxygen difference were not significant statistically (Table II). Therefore it is believed that the decrease in cardiac output during 1-nor-epinephrine infusion does not represent congestive heart failure (1). The striking increase in peripheral venous pressure observed in Subject F. H., reaching its peak earlier than the peak rise in right atrial pressure during the 1-nor-epinephrine infusion, suggests that increased peripheral venous tone may indeed be responsible for the rise in intra-atrial pressure by decreasing the capacity of the vascular system. The change here is quite unlike that in congestive heart failure, where the gradient between pressure in peripheral veins and right atrium is diminished rather than increased (17), the pressure in the two sites often becoming almost equal as the pressure rises.

One must also consider the possibility that peripheral venous constriction is the mechanism primarily responsible for the hypertension induced by 1-nor-epinephrine in the systemic circuit. Since a rise of $20 \mathrm{~mm}$. $\mathrm{Hg}$, the observed mean elevation in mean peripheral arterial pressure, was much greater than any of the measured increases in mean right auricular pressure (this relationship holding true in the three cases where both pressures were determined) and since the cardiac output is decreased or unchanged after 1-nor-epinephrine, one is justified in stating that there is definite increase in systemic peripheral resistance during administration of the drug. In one case where systemic peripheral resistance was calculated, there was a striking increase of $82 \%$ during 1 -norepinephrine. Thus one may conclude that arterial or capillary constriction contributes to the observed increase in total peripheral resistance despite the rise in right atrial pressure.

\section{SUMMARY AND CONCLUSIONS}

The hemodynamic response of 13 subjects to the infusion of 1-nor-epinephrine was studied. During 1-nor-epinephrine infusion, the following changes occurred: a statistically significant mean rise in pulmonary artery pressure; a significant rise 
in mean brachial artery pressure; a decrease in the cardiac output in five subjects, remaining unchanged in five. There was a statistically significant mean rise in pulmonary "capillary" pressure. There was a statistically significant increase in total peripheral resistance. There was no significant increase in pulmonary arteriolar resistance. There was a definite and marked rise in right atrial pressure in each of three subjects.

It is concluded that the pulmonary hypertension seen during the administration of 1-nor-epinephrine is not due to constriction of the pulmonary arteries, but rather to an increase in pulmonary venous pressure; it is also concluded that 1-nor-epinephrine produces constriction of peripheral arteries or capillaries as well as peripheral veins.

\section{ACKNOWLEDGMENT}

The authors gratefully acknowledge the technical assistance of Mrs. Mary Damron and Mr. Harold Perlman.

\section{REFERENCES}

1. Goldenberg, M., Pines, K. L., Baldwin, E. de F., Greene, D. G., and Roh, C. E., The hemodynamic response of man to nor-epinephrine and epinephrine and its relation to the problem of hypertension. Am. J. Med., 1948, 5, 792.

2. Pitcairn, D. M., and Youmans, W. B., The nature of pressor substances in pheochromocytomas. Circulation, 1950, 2, 505.

3. Youmans, W. B., Visceral functions of the nervous system. Ann. Rev. Physiol., 1949, 11, 139.

4. Hellems, H. K., Haynes, F. W., Dexter, L., and Kinney, T. D., Pulmonary capillary pressure in animals estimated by venous and arterial catheterization. Am. J. Physiol., 1948, 155, 98.

5. Dexter, L., Dow, J. W., Haynes, F. W., Whittenberger, J. L., Ferris, B. G., Goodale, W. T., and Hellems, H. K., Studies of the pulmonary circulation in man at rest. Normal variations and the interrelations between increased pulmonary blood flow, elevated pulmonary arterial pressure, and high pulmonary "capillary" pressures. J. Clin. Invest., $1950,29,602$.

6. Cournand, A., Some aspects of the pulmonary circulation in normal man and in chronic cardiopulmonary diseases. Circulation, 1950, 2, 641.

7. Cournand, A., and Ranges, H. A., Catheterization of the right auricle in man. Proc. Soc. Exper. Biol. \& Med., 1941, 46, 462.

8. Fowler, N. O., Westcott, R. N., Hauenstein, V. D., Scott, R. C., and McGuire, J., Observations on autonomic participation in pulmonary arteriolar resistance in man. J. Clin. Invest., 1950, 29, 1387.

9. Fisher, R. A., Statistical Methods for Research Workers, Section 13. Oliver \& Boyd, London, 1950, 11th edition.

10. Fisher, R. A., and Yates, F., Statistical Tables for Biological, Agricultural and Medical Research. Oliver \& Boyd, London, 1938.

11. Guilford, J. P., Fundamental Statistics in Psychology and Education. McGraw-Hill Book Company, Inc., New York, 1942.

12. Judson, W. E., Epstein, F. H., and Wilkins, R. W., The comparative effects of small intravenous doses of 1-nor-epinephrine upon arterial pressure and pulse rate in normotensive subjects and in hypertensive patients before and after thoracolumbar sympathectomy. J. Clin. Invest., 1950, 29, 1414.

13. Stead, E. A., Jr., and Warren, J. V., Cardiac output in man; analysis of mechanisms varying cardiac output based on recent clinical studies. Arch. Int. Med., 1947, 80, 237.

14. Ranges, H. A., and Bradley, S. E., Systemic and renal circulatory changes following the administration of adrenin, ephedrine, and paredrinol to normal man. J. Clin. Invest., 1943, 22, 687.

15. Bradley, S. E., and Parker, B., The hemodynamic effects of angiotonin in normal man. J. Clin. Invest., 1941, 20, 715.

16. Iglauer, A., and Altschule, M. D., The effect of paredrine on the venous system. J. Clin. Invest., 1940, 19, 503.

17. Factors Regulating Blood Pressure, Tr. Third Conf., edited by Zweifach, B. W., and Shorr, E. Josiah Macy, Jr. Foundation, New York, 1949. 